\title{
Experimental evaluation of precision and accuracy of RSA in the lumbar spine
}

\author{
Marie Christina Keller ${ }^{1} \cdot$ Christof Hurschler $^{1} \cdot$ Michael Schwarze $^{1} \mathbb{C}$
}

Received: 22 June 2020 / Revised: 4 November 2020 / Accepted: 17 November 2020 / Published online: 4 December 2020

(c) The Author(s) 2020

\begin{abstract}
Purpose Roentgen stereophotogrammetric analysis is a technique to make accurate assessments of the relative position and orientation of bone structures and implants in vivo. While the precision and accuracy of stereophotogrammetry for hip and knee arthroplasty is well documented, there is insufficient knowledge of the technique's precision and, especially accuracy when applied to rotational movements in the spinal region.

Methods The motion of one cadaver lumbar spine segment (L3/L4) was analyzed in flexion-extension, lateral bending and internal rotation. The specific aim of this study was to examine the precision and accuracy of stereophotogrammetry in a controlled in vitro setting, taking the surrounding soft tissue into account. The second objective of this study was to investigate the effect of different focal spot values of X-ray tubes.

Results Overall, the precision of flexion-extension measurements was found to be better when using a $0.6 \mathrm{~mm}$ focal spot value rather than $1.2 \mathrm{~mm}\left( \pm 0.056^{\circ}\right.$ and $\pm 0.153^{\circ}$; respectively $)$, and accuracy was also slightly better for the $0.6 \mathrm{~mm}$ focal spot value compared to $1.2 \mathrm{~mm}\left(-0.137^{\circ}\right.$ and $-0.170^{\circ}$; respectively). The best values for precision and accuracy were obtained in lateral bending for both $0.6 \mathrm{~mm}$ and $1.2 \mathrm{~mm}$ focal spot values (precision: $\pm 0.019^{\circ}$ and $\pm 0.015^{\circ}$, respectively; accuracy: $-0.041^{\circ}$ and $-0.035^{\circ}$ ).

Conclusion In summary, the results suggest stereophotogrammetry to be a highly precise method to analyze motion of the lumbar spine. Since precision and accuracy are better than $0.2^{\circ}$ for both focal spot values, the choice between these is of minor clinical relevance.
\end{abstract}

Keywords RSA $\cdot$ In-vitro $\cdot$ Validation $\cdot$ Lumbar spine

\section{Introduction}

Roentgen stereophotogrammetric analysis (RSA) is used to make accurate assessments of the relative position and orientation of bone structures and implants in vivo. Application of the technique allows the detection of clinically relevant motion, or the lack thereof. In this technique, two $\mathrm{X}$-ray images are taken simultaneously from different directions in order to perform a three-dimensional rigid body movement analysis [1]. Clinical applications of RSA in the spinal context have included verification of the rigidity of spinal fusions and evaluation of dynamic stabilization of the

Michael Schwarze

Schwarze.michael@mh-hannover.de

1 Laboratory for Biomechanics and Biomaterials, Hannover Medical School, Anna-von-Borries-Str. 1-7, 30625 Hannover, Germany cervical, thoracic and lumbar spine [2-12]. In hip and knee arthroplasty, RSA has been widely used to analyze migration of implants (relative motion of bone and implant), due to its high precision and accuracy. The accuracy of marker-based RSA for rotational measurements is $0.18^{\circ}$ (with a precision of $0.5^{\circ}$ ) for hip stems [13]; and $0.12^{\circ}$ (with a precision of $0.02^{\circ}$ ) for knee femoral components [14].

For movement analysis in the area of the lumbar spine, the X-rays must pass through a greater volume of soft tissue than is the case for the major joints of the extremities. This occurrence could reduce the precision and accuracy of the technique. The voluminous soft tissue surrounding the spine introduces scattering of the beam, which attenuates image contrast and leads to a loss in analysis quality [15, 16]. Nonetheless, due to difficulties in representing soft-tissue effects realistically in phantom studies, previous in vitro studies of RSA accuracy for the spine did not focus on the simulation of soft tissue effects [14]. 
Although double examinations are recommended as a validation of RSA accuracy in clinical applications (ISO 16,087-2013), it must be considered that only precision (repeatability)—and not accuracy_can be determined by this method, since the known true value for comparison is not available $[17,18]$. It should be noted that some literature published before ratification of the RSA standard ISO 16,087-2013 makes different use of the terms precision and accuracy then defined in the standard. Thus, care should be taken when interpreting the "accuracy" reported in various publications. The translational and rotational "accuracy" reported by Johnsson et al. [12] in a clinical assessment of spinal motion would better be describes as precision according to ISO 16,087-2013. Even in later literature, differentiation between precision and accuracy is not always respected. An example of this is evident in the review by Humadi et al., where some historic studies are cited as reporting accuracy, whereas the data were originally reported as a measure of precision with respect to the ISO standard [19].

The indisputable benefit of double examinations in clinical applications is ethically controversial due to the subjection of the patients to additional radiation exposure [20]. This is particularly true for X-ray images of the trunk, which expose many vital organs. For this reason along with the possibility of being able to determine accuracy and not only precision, an experimental phantom approach was chosen for our investigation.

Since the accuracy of the RSA method for applications in the spine has not been sufficiently characterized to date, the first goal of this study was to examine the precision and accuracy of RSA in a spinal motion-segment analysis, taking the surrounding soft tissue into account using a substitute material (nylon 6).

Another potential source of RSA measurement error is the size of the X-ray source focal spot, which has not been investigated in this context, prior to this study. Statements by authors such as H. Koehnle and Göran Selvik, one of the creators of RSA, imply that the use of the smallest possible focal spot could potentially improve RSA accuracy $[1,21]$. Reducing the size of the focal spot minimizes geometrical blur resulting from the partial shade introduced by a finite small X-ray emission area (Fig. 1) [1, 16, 21]. Nonetheless, in clinical applications of spinal RSA, a larger focal spot has commonly been used to reduce thermal load on the X-ray tubes [22]. However, the low current-time product of RSA image acquisition falls well below the capabilities of modern tubes.

Therefore, the second objective of this in-vitro study was to compare the precision and accuracy of RSA using different nominal focal spot values (FSVs), to investigate whether clinical RSA could benefit from the use of a smaller focal spot.

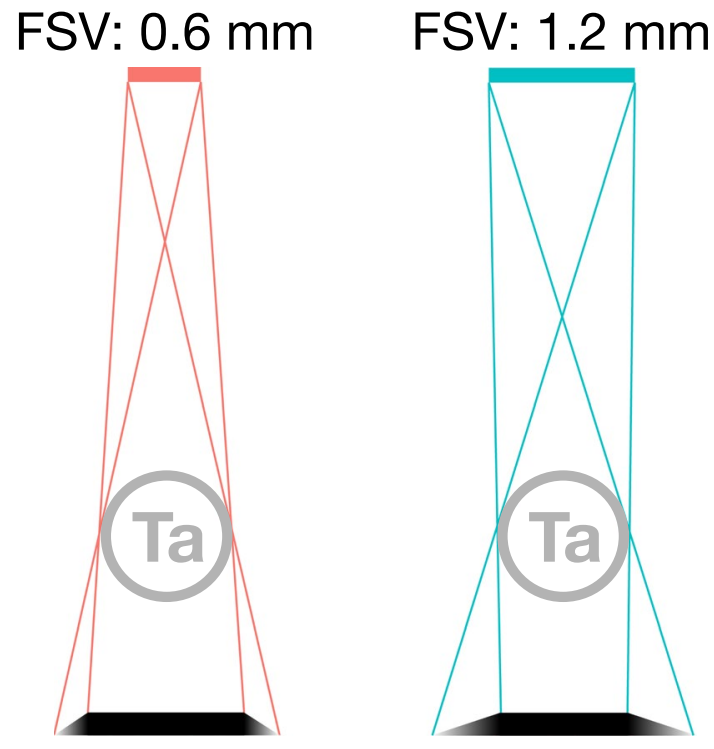

Fig. 1 The extent of partial shade (bottom) caused by a tantalum bead (Ta), as a function of size of the FSV in the X-ray tube (top). The height of the black bar is proportional to the shadow of the tantalum bead with partial shades on both sides. The sizes of the FSV, tantalum beads and shade are approximately to scale, but exaggerated with respect to the actual distances. The proportion of distances reflects clinical practice

\section{Methods}

To assess the precision and accuracy of RSA, the relative motions of two human macerated lumbar vertebrae (L3 and L4) were analyzed. The vertebrae were mounted onto a multi-axis micromanipulator (M-37 with SM13, Newport, Darmstadt, Germany). This allowed the vertebrae to be tilted, in order to simulate physiological flexion-extension, lateral bending and axial rotations (Fig. 2).

Flexion-extension can be regarded as the most relevant axis of motion in spine diagnostics [5, 6, 23]. The rotational accuracy of the micromanipulator is $0.0001^{\circ}$ (SD $0.007^{\circ}$ ) [24]. The vertebrae were attached to the micromanipulator by means of square carbon tubes to reduce the effects of bending and obscuring in the X-ray images to a minimum. Different carbon mounts were designed for each axis of rotation, to ensure that the center of rotation of the vertebrae would be situated in its physiological position during every motion $[25,26]$. The center of rotation was placed based on the work of Xia et al. incorporating an approximated scaling factor of 1.13 to account for the actual size of the used vertebrae (length: L3: $84.5 \mathrm{~mm}$; L4: 82.9) [26]. In the anterior-posterior dimension, the center of rotation is located $23 \mathrm{~mm}$ dorsal of the anterior edge of L3 for flexion/extension, and $36 \mathrm{~mm}$ ventral for internal rotation. For lateral bending, the center of rotation 


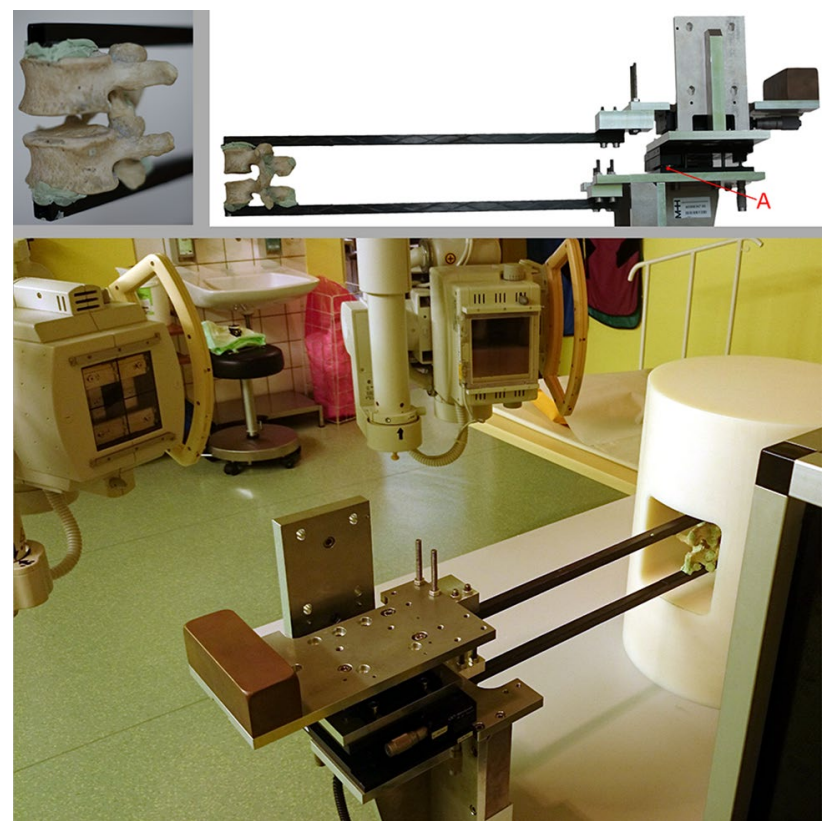

Fig. 2 Experimental setup for lateral bending. Top left: Fixation of the spine segment to the carbon tubes. Top right: The manipulator observed from one side: 'A' denotes the center of rotation in the manipulator. The axis of rotation runs through this point parallel to the carbon tubes. Main image: Two X-ray tubes in front of the phantom with the spine segment inside

was placed in the center of the top surface of the vertebral body. Five tantalum markers, each of $1 \mathrm{~mm}$ diameter, were attached to each vertebra's surface using bone cement (Palacos LV, Heraeus Medical GmbH, Wehrheim, Germany), according to a typical clinical distribution: one marker on the spinous process and four on the lamina (Fig. 3) [5]. The cement was also used to fix the vertebrae on the carbon mounts.

\section{Nylon phantom}

To simulate the soft tissue's attenuation and scattering of $\mathrm{X}$-rays during clinical RSA procedures, a custom-made phantom made of nylon 6 was designed. The phantom was cylindrical in form with an opening for the vertebral segment; it represents the soft tissue surrounding the lumbar spine. Nylon 6 was chosen, since Mann et al. found this to be a good simulation material for soft tissue exposed to X-rays in the diagnostic photon energy range [27].

\section{RSA-Setup}

Two X-ray tubes (SRO3310 ROT 360, Philips, Amsterdam, The Netherlands) were arranged in accordance with a typical clinical RSA-setup at a distance of $1.6 \mathrm{~m}$ from the picture plane, facing the vertebrae at an angle of $20^{\circ}$ to the normal

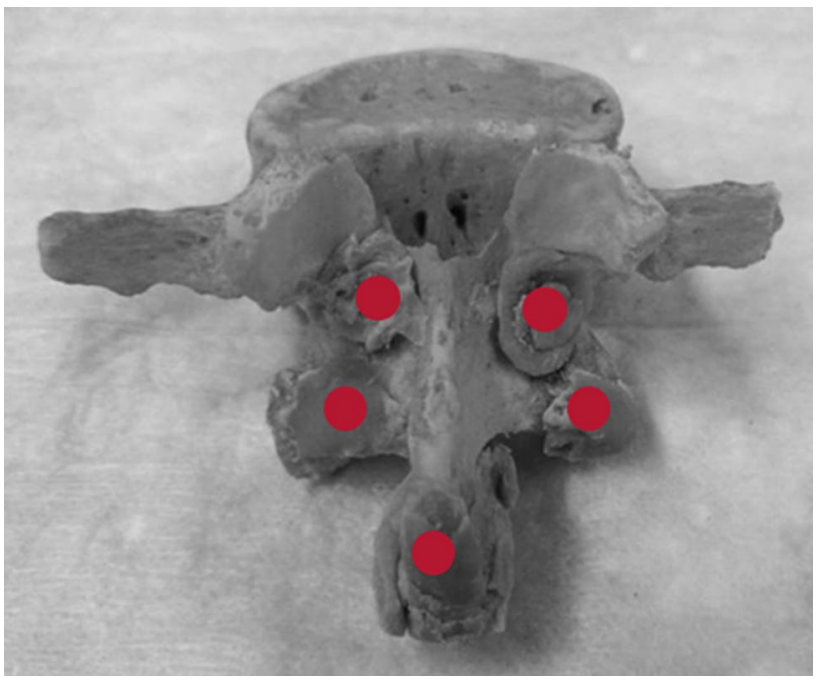

Fig. 3 Marker distribution of the tantalum markers, similar to the clinical distribution of Daentzer et al. [5]

of the image plane $[3-5,28]$. The calibration box (CarbonBoxLeiden10, Medis Medical Imaging Systems bv., Leiden, The Netherlands) was situated between the image plane and the vertebrae, along with the calibration and fiducial markers necessary for the three-dimensional reconstruction of the vertebral poses. The images were recorded on cassettes $(35 \times 43 \mathrm{~cm}$ IP Cassette Type CC, Fuji, Tokio, Japan) and digitized with a resolution of 125 dpi (PCR Eleva Corado, Philips, Amsterdam, The Netherlands). Every scene, consisting of two simultaneous X-rays, was captured at $20 \mathrm{mAs}$ and $125 \mathrm{kV}$, from a lateral perspective consistent with that used in a the clinical setting of Daentzer et al. [5]. The coordinate system was oriented such that rotation about the $\mathrm{x}$-axis corresponds to flexion-extension, rotation about the y-axis corresponds to axial rotation and rotation about the z-axis corresponds to lateral bending. The flexion-extension-axis ( $\mathrm{x}$-axis) is perpendicular to the image plane; the other axes ( $\mathrm{y}$ and $\mathrm{z}$ ) are oriented parallel to the image plane.

The Model-based RSA software (MBRSA) (Version 3.31, Medis specials bv., Leiden, The Netherlands) was used for analysis of the stereoscopic X-ray data. Every micromanipulator adjustment and every RSA evaluation were conducted exclusively by the same individual.

For each axis of rotation and for each focal spot value FSV $(0.6 \mathrm{~mm}$ and $1.2 \mathrm{~mm})$, six repetitions of three conditions were executed. The three conditions were: the reference scene, the zero-relative-motion scene (ZRM, no movement), and the relative-motion scene (RLM). The latter scene was obtained by tilting one vertebra through $2.62^{\circ}$ in axial rotation and through rotations of $5.23^{\circ}$ in flexion-extension and lateral bending around the center of rotation of the spinal segment. These odd numbers resulted from applying $10 \mathrm{~mm}$ of translation on the micrometer drives. 
Each zero-relative-motion scene was analyzed with reference to its preceding reference scene. This procedure is the equivalent of a clinical double examination and the true motion is always zero. However, the observed motion between these scenes will not be exactly zero and repeated measures allow the calculation of the precision of the procedure.

For determination of the accuracy of the technique, the RLM scenes were compared to their corresponding reference scene. Here the micromanipulator functioned as the highly accurate standard, and the accuracy was determined from the average difference between the analyzed rotation and the respective micrometer setting.

The data were analyzed using the MBRSA software to determine rotation relative to the calibration box's coordinate system. Since the executed movement did not necessarily rotate exclusively about one single axis at a time, the resulting total angle of rotation was calculated from the three rotational components, for all 72 cases which were considered. This calculation allowed a direct comparison of the measured angle to that set by the micromanipulator.

RSA evaluation parameters (fiducial marker error, control marker errors, rigid-body-error (RBE), rigid body fitting error and condition number) were recorded according to recommendations [20,28].

Precision was calculated by: precision $=t * \sigma * 1 / \sqrt{n}$, with $\mathrm{t}$ as a value from the $\mathrm{t}$-distribution for a $95 \%$ confidence interval (CI) and $n$ - 1 degrees of freedom, $\sigma$ the standard deviation and $n$ the number of observations $(n=6)[29,30]$. Accuracy was defined as the mean difference between the true value as obtained from the manipulators and the measured value from RSA analysis [31].

\section{Results}

The RSA analysis was successful for each of the captured scenes. Thus, for each measurement ( $n=72$ in total), it was possible to compare the respective rotations measured with RSA and with the micromanipulator setting, both in the ZRM and RLM protocols.

The precision of flexion-extension was higher when using the $0.6 \mathrm{~mm}$ FSV, when compared to the $1.2 \mathrm{~mm}$ FSV $\left( \pm 0.056^{\circ} ; \pm 0.153^{\circ}\right.$, respectively, Table 1$)$, and the accuracy was slightly better for the $0.6 \mathrm{~mm}$ compared to the $1.2 \mathrm{~mm}$ FSV $\left(-0.137^{\circ} ;-0.170^{\circ}\right.$, respectively, Table 2$)$.

When comparing results for the respective axes of rotation, the best precision was obtained for lateral bending, both for an FSV of $0.6 \mathrm{~mm}$ and for an FSV of $1.2 \mathrm{~mm}$ $\left( \pm 0.019^{\circ}\right.$ and $\pm 0.015^{\circ}$, respectively, Table 1$)$. The best overall accuracy was also achieved for lateral bending (FSV $0.6 \mathrm{~mm}$ : $-0.041^{\circ}$; FSV $1.2 \mathrm{~mm}$ : $-0.035^{\circ}$; Table 2). The worst accuracy appeared for axial rotation using the $1.2 \mathrm{~mm} \mathrm{FSV}\left(0.174^{\circ}\right)$ (Fig. 4). No clear difference in either the precision or accuracy could be detected between rotation about a perpendicular-to-image-plane axis and the in-plane-axes.

The contrast between markers and the background was better in the images with an FSV of $0.6 \mathrm{~mm}$, compared to an FSV of $1.2 \mathrm{~mm}$ (Fig. 5).

Concerning the RSA evaluation parameters, the fiducial marker error was $<0.2 \mathrm{~mm}$ and the control marker errors were found to be $\leq 1 \mathrm{~mm}$. The RBE was between $0.001 \mathrm{~mm}$ and $0.117 \mathrm{~mm}$ and the mean rigid body fitting error was $0.04 \mathrm{~mm}$. The condition number, representing the quality of spatial marker distribution, ranged from 29.1 to 35.6.
Table 1 Precision of zerorelative-motion (ZRM) analysis: motion between two reference scenes is calculated. True motion is zero in all directions. All values represent rotations and are therefore given in degrees

\begin{tabular}{|c|c|c|c|c|c|c|}
\hline \multirow{2}{*}{$\begin{array}{l}\text { Nominal focal spot } \\
\text { value (FSV) }\end{array}$} & \multicolumn{2}{|c|}{ Flexion-extension } & \multicolumn{2}{|c|}{ Lateral bending } & \multicolumn{2}{|c|}{ Axial rotation } \\
\hline & $0.6 \mathrm{~mm}$ & $1.2 \mathrm{~mm}$ & $0.6 \mathrm{~mm}$ & $1.2 \mathrm{~mm}$ & $0.6 \mathrm{~mm}$ & $1.2 \mathrm{~mm}$ \\
\hline Average Bias & 0.006 & -0.004 & -0.001 & -0.001 & 0.010 & -0.003 \\
\hline SD & 0.053 & 0.146 & 0.018 & 0.014 & 0.086 & 0.037 \\
\hline Precision $(95 \% \mathrm{CI})$ & \pm 0.056 & \pm 0.153 & \pm 0.019 & \pm 0.015 & \pm 0.090 & \pm 0.038 \\
\hline Repetitions (n) & 6 & 6 & 6 & 6 & 6 & 6 \\
\hline
\end{tabular}

for axial rotation, respectively. All values represent rotations and are therefore given in degrees
Table 2 Accuracy of relative-motion (RLM) analysis: Movement is calculated between one reference scene and one moved scene. True motion is $5.23^{\circ}$ for flexion-extension and lateral bending and $2.62^{\circ}$

\begin{tabular}{|c|c|c|c|c|c|c|}
\hline \multirow{2}{*}{$\begin{array}{l}\text { Nominal focal spot value } \\
\text { (FSV) }\end{array}$} & \multicolumn{2}{|c|}{ Flexion-extension } & \multicolumn{2}{|c|}{ Lateral bending } & \multicolumn{2}{|c|}{ Axial rotation } \\
\hline & $0.6 \mathrm{~mm}$ & $1.2 \mathrm{~mm}$ & $0.6 \mathrm{~mm}$ & $1.2 \mathrm{~mm}$ & $0.6 \mathrm{~mm}$ & $1.2 \mathrm{~mm}$ \\
\hline Accuracy & -0.137 & -0.170 & -0.041 & -0.035 & 0.012 & -0.174 \\
\hline Repetitions (n) & 6 & 6 & 6 & 6 & 6 & 6 \\
\hline
\end{tabular}


Flexion

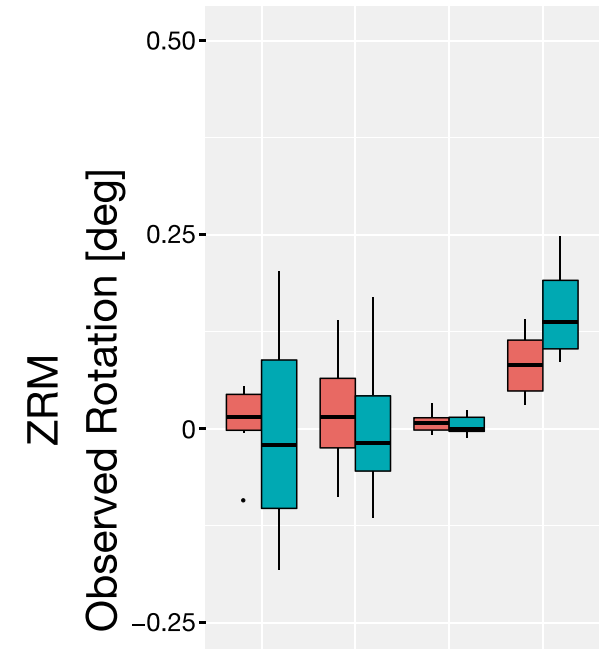

FSV

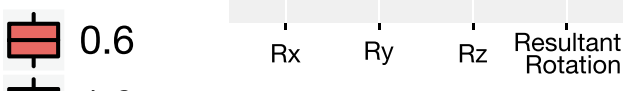

1.2
Lateral Bending

$0.50-$

0.25-

0-

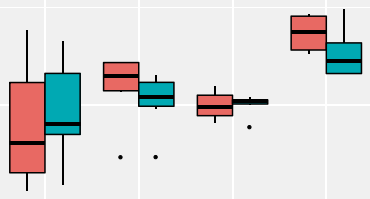

$-0.25-$

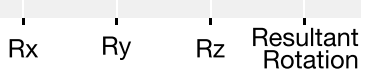

$0.50-$

0.25

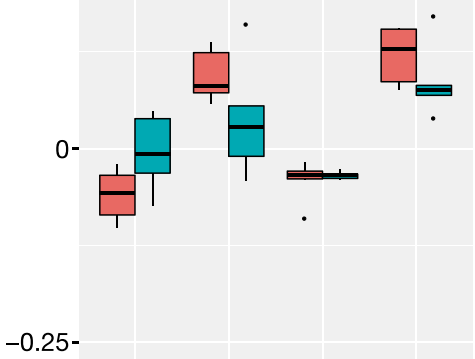

Rx Ry Rz $\begin{gathered}\text { Resultant } \\ \text { Rotation }\end{gathered}$
Axial Rotation

$0.50-$

$0.25-$

0 -

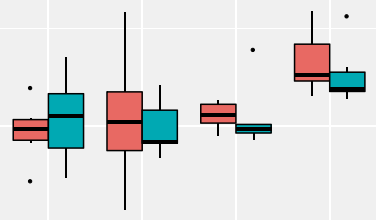

$-0.25-$

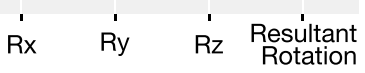

0.50-

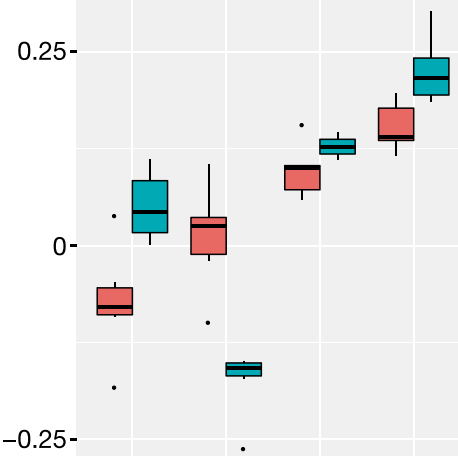

'Rx Ry Rz Resultant

Fig. 4 Observed rotation for zero-relative-motion (ZRM) (top row) and deviation from expected motion for relative-motion (RLM) (bottom row), using an FSV of $0.6 \mathrm{~mm}$ and an FSV of $1.2 \mathrm{~mm}$, respectively, shown for flexion-extension, lateral bending and axial rotation

\section{Discussion}

The focus of this study was to assess the precision and accuracy of RSA in a spinal application, whilst taking the soft tissue surrounding the lumbar spine into account by integrating a soft tissue phantom. We found a precision ranging from $\pm 0.019^{\circ}$ to $\pm 0.153^{\circ}$ and an accuracy ranging from $0.012^{\circ}$ to $-0.17^{\circ}$, among all of the movements investigated using the ZRM and RLM protocols, respectively. We also observed an effect of FSV, which suggests that variations in this parameter can be used to increase the accuracy of angle measurements in clinical studies of spinal kinematics.

The RSA evaluation parameters were similar to those of clinical lateral lumbar roentgen stereophotogrammetry images from a previous study [5] and met all relevant thresholds from recommendations ( $\mathrm{RBE}<0.5 \mathrm{~mm}$ [28], rigid body 


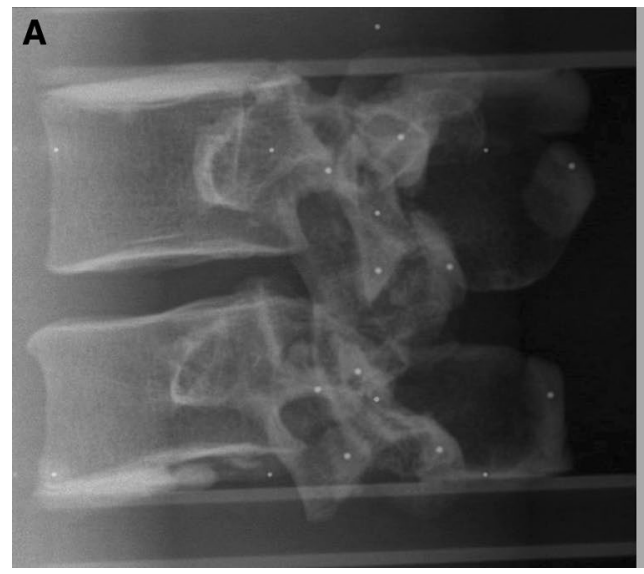

B

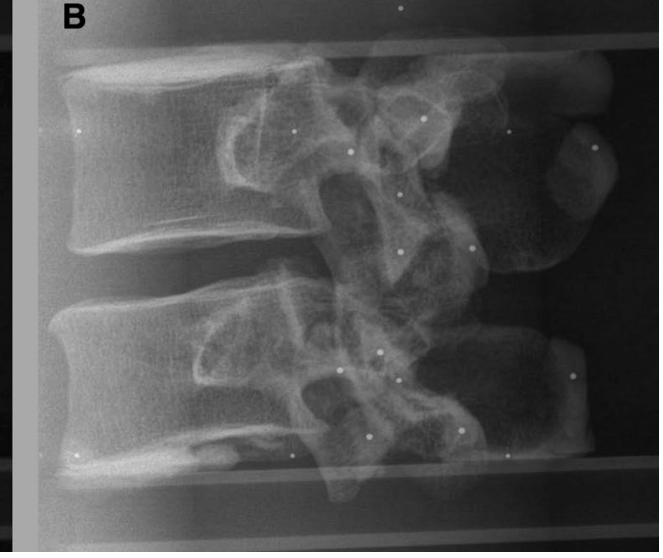

Fig. 5 Contrast between markers and the background depending on FSV: $1.2 \mathrm{~mm}(\mathrm{~A}), 0.6 \mathrm{~mm}$ (B)

Table 3 Precision for rotational movements as originally determined by double examination in clinical RSA studies. All values represent rotations and are therefore given in degrees. CI means confidence interval

\begin{tabular}{lllll}
\hline Study & $\begin{array}{l}\text { Flexion- } \\
\text { extension }\end{array}$ & $\begin{array}{l}\text { Lateral bend- } \\
\text { ing }\end{array}$ & Axial rotation & Definition \\
\hline Zoega [10] & 4 & 2 & 3.7 & $99 \%$ CI \\
Johnsson [12] & 1.89 & 0.78 & 0.43 & $99 \%$ CI \\
Halldin [8] & 2.74 & 1.08 & 0.88 & $99 \%$ CI \\
Lind [11] & 1.53 & 1.50 & 1.10 & $95 \%$ CI \\
Nabhan [9] & 4.2 & 1.5 & 3.9 & $99 \%$ CI \\
\hline
\end{tabular}

fitting error $<0.35 \mathrm{~mm}[20]$ and condition number $<100[20$, 32]).

The effect of the improved contrast obtained with an FSV of $0.6 \mathrm{~mm}$ compared to an FSV of $1.2 \mathrm{~mm}$ can be observed in the improved precision and accuracy obtained for this FSV, especially in flexion-extension. In lateral bending, results for the two FSVs are comparable and in axial rotation a better accuracy is observed for the smaller FSV. However, even the lower accuracy obtained with the larger FSV should still be sufficient for most clinical questions, since the accuracies for both FSVs are better than $0.2^{\circ}$.

Since there are a number of clinical studies using RSA for the determination of movements in the spine, the precision of rotations was determined repeatedly by double examinations (Table 3 ). The results range from $1.5^{\circ}$ to $4.2^{\circ}$ in flexion-extension, from $0.8^{\circ}$ to $2^{\circ}$ in lateral bending and from $0.4^{\circ}$ to $3.9^{\circ}$ in axial rotation, respectively. This is considerably higher than the precision values in our study which are all below $0.2^{\circ}$. This huge difference might be explained by the fact that during a real double examination in a clinical context, the position of the spinal segment is not as stable and, especially the marker distribution is not as ideal (median condition number in this study: 30.6, while for usual clinical cases, e.g., Daentzer et al. it was 70.3) as in our context.

There are a number of previous in-vitro RSA studies reporting precision and accuracy. Lee et al. performed an in-vitro study assessing the accuracy of RSA in spinal examination before the advent of fully computerized image processing [33]. They found the accuracy as defined as rootmean-squared error to be $0.14^{\circ}$ for flexion-extension and $0.08^{\circ}$ for axial rotation, which is in close agreement with our results. Results of an employed soft tissue model were not separately reported and the range of motions was up to $20^{\circ}$, which present methodological differences to the presented study.

Seehaus et al. compared the precision and accuracy of marker- and model-based RSA in a phantom model study of knee and hip implants [24]. Using the same rotational micrometers as in our setup, they conducted rotations of $1.19^{\circ}$ about the anterior-posterior axis, (perpendicular-toplane rotation, corresponding to the flexion-extension axis in the present study) and of $1.31^{\circ}$ about the other axes. The surrounding bones and soft tissues were simulated by two hollow cylinders of polymethylmethacrylate. For the markerbased RSA of hip implants, Seehaus et al. found a precision of $\pm 0.050^{\circ}$ (for perpendicular-to-plane rotation) with a worst case (around the superior-inferior axis) of $\pm 0.230^{\circ}$, which is comparable regarding the perpendicular-to-plane rotation, but inferior to the other axes in the presented study $(0.6 \mathrm{~mm}$ FSV: $\pm 0.056^{\circ}$ for perpendicular-to-plane rotation, $\pm 0.019^{\circ}$ and $\pm 0.090^{\circ}$ for other axes). This difference in precision is likely attributed to the longitudinal marker distribution along the superior-inferior axis in hip RSA, which is not present in spinal RSA. Regarding accuracy, Seehaus et al. found values between $-0.013 \mathrm{~mm}$ and $0.030 \mathrm{~mm}$ for marker-based analysis of hip implants, which is superior to the accuracy in the presented study $\left(-0.174^{\circ}\right.$ to $\left.0.012^{\circ}\right)$ [24]. This can be attributed to the smaller soft tissue model in the study of 
Seehaus et al. which accurately reflects the situation in the hip region as seen in the anterior-posterior direction.

The influence of marker number and spatial distribution on the precision and accuracy of RSA of tibial plateau fractures were examined by Solomon et al. in a plastic tibia model [14]. The experimental setup did not include a soft tissue phantom. Solomon et al. analyzed a marker distribution that they had found to be sufficient and applicable (6 markers defining proximal tibia and fractured fragment each). They found the rotational accuracy to be better than $0.123^{\circ}$ (in the sagittal plane), which is slightly superior to the results from our study (accuracy better than $-0.174^{\circ}$ ). This can once again be attributed to the presence of a soft tissue phantom in the presented study. The precision was measured to be $\pm 0.024^{\circ}$, which is again superior to our results. In the in vivo validation analyses of 12 tibial plateau fracture patients, precision values of $\pm 0.331^{\circ}, \pm 0.260^{\circ}$ and $\pm 0.165^{\circ}$ were measured for $\mathrm{x}$ - (lateral), $\mathrm{y}$-(distal), and $\mathrm{z}$-(posterior) axes, respectively [14]. This highlights the difference between the idealized in-vitro setting and the clinical reality, even when only small soft tissue effects should be present as around the tibia.

Bojan et al. examined the precision and accuracy of RSA in the context of screw cut-out in trochanteric hip fractures, in vitro with a plastic femur model [13]. Five tantalum markers were attached to the femoral head, the shaft fragment carried eight such markers, and the lag screw and intramedullary nail carried four tantalum markers each. They did not include a soft tissue phantom and no dynamic double examinations were conducted. The precision was found to be better than $0.5^{\circ}$, which is inferior to the results of the presented study (precision better than $\pm 0.153^{\circ}$ ), and the accuracy for rotations of the femoral head was found to be better than $0.18^{\circ}$, which is comparable to the results of the presented study (accuracy better than $-0.170^{\circ}$ ) [13].

Several limitations regarding the current study should be mentioned, none of which substantially affected the results and conclusions.

First, all patients have individual marker distributions which can have an effect on analysis quality, especially in the examination of rotational movement $[13,14,20,32$, 34-36]. In the current study, only one marker distribution was analyzed. While this marker distribution was superior to the usual clinical situation (median condition number for this study was 30.6, while e.g., for Daentzer et al. it was 70.3), the range of motion (flexion extension: this study: $5.23^{\circ}$, Daentzer et al.: $2.9^{\circ}-7.1^{\circ}$ ) and image quality closely reflect the situation found in practice [5].

Second, the human body consists of different soft tissues which attenuate X-rays differently, and the tissues in each body are shaped individually [15]. The nylon phantom used in this study represents only the average
X-ray attenuation characteristics of average soft tissue. The sample itself does not contain soft tissues such as a vertebral disk. This is not likely to influence the results, since the markers would not be affected by the added $\mathrm{x}$-ray attenuation.

Third, only a single segment was analyzed in this study. However, the technical challenge to incorporate the correct centers of rotation was deemed disproportional given the fact that many clinical RSA studies focus on one single treated segment [5, 7-11].

Fourth, despite efforts to minimize the bending of the carbon tubes of the manipulator, they displayed a maximum deflection under their own weight and the weight of the vertebrae of $0.13 \mathrm{~mm}$ in the worst case (flexion extension). Since both tubes were affected likewise, neither the location of the center of rotation between the vertebrae nor the rotation itself was biased considerably.

Fifth, the setup for the examination of axial rotation was moved between the experimental procedure conducted for an FSV of $0.6 \mathrm{~mm}$ and the procedure conducted for an FSV of $1.2 \mathrm{~mm}$, since they could not be conducted in succession on the same day due to clinical processes. This led to a slight change in axis of rotation and spatial test arrangement between the test series. However, the effect of this misalignment on the results obtained is regarded as minimal.

Sixth, in order to apply the results of this study to the clinical use of RSA, it must be considered that no movement occurred during the $\mathrm{X}$-ray exposure time in the experimental in vitro setting. A patient's body will execute motion during examination, although this effect is minimal in a stable sideways position of the patient.

In summary, the results show a precision of $\pm 0.153^{\circ}$ and an accuracy of $0.170^{\circ}$ for an FSV of $1.2 \mathrm{~mm}$, suggesting RSA to be a highly precise method for analyzing motion of the lumbar spine. The determination of accuracy and precision of RSA measurements of spinal motion will allow researchers to differentiate between clinically relevant spine motion and measurement error. In particular, this is relevant for the accuracy, which cannot be determined by double examinations. Nevertheless, the idealized circumstances of this in-vitro test should always be considered. The findings for the larger FSV are of more relevance, since it is the one commonly used in the clinical field. Our results show that it has an only slightly inferior precision and accuracy, compared to the smaller FSV [22].

Acknowledgements The authors wish to thank the Department of Radiology for their cooperation in performing the RSA examinations, especially Saida Bayramova, Holger Kleinschmidt and Gabriele Hauke. 
Funding Open Access funding enabled and organized by Projekt DEAL.

\section{Compliance with ethical standards}

Conflict of interest None of the authors has any potential conflicts of interest to declare.

Open Access This article is licensed under a Creative Commons Attribution 4.0 International License, which permits use, sharing, adaptation, distribution and reproduction in any medium or format, as long as you give appropriate credit to the original author(s) and the source, provide a link to the Creative Commons licence, and indicate if changes were made. The images or other third party material in this article are included in the article's Creative Commons licence, unless indicated otherwise in a credit line to the material. If material is not included in the article's Creative Commons licence and your intended use is not permitted by statutory regulation or exceeds the permitted use, you will need to obtain permission directly from the copyright holder. To view a copy of this licence, visit http://creativecommons.org/licenses/by/4.0/.

\section{References}

1. Selvik G (1989) Roentgen stereophotogrammetry. A method for the study of the kinematics of the skeletal system. Acta Orthop Scand Suppl 232:1-51

2. Olsson TH, Selvik G, Willner S (1976) Kinematic analysis of spinal fusions. Invest Radiol 11:202-209. https://doi.org/10.1097/00004 424-197605000-00008

3. Johnsson R, Selvik G, Strömqvist B, Sundén G (1990) Mobility of the lower lumbar spine after posterolateral fusion determined by roentgen stereophotogrammetric analysis. Spine (Phila Pa 1976) 15:347-350. https://doi.org/10.1097/00007632-199005000-00001

4. Gunnarsson G, Axelsson P, Johnsson R, Strömqvist B (2000) A method to evaluate the in vivo behaviour of lumbar spine implants. Eur Spine J 9:230-234. https://doi.org/10.1007/s005860000143

5. Daentzer D, Hurschler C, Seehaus F et al (2016) Posterior dynamic stabilization in the lumbar spine-24 months results of a prospective clinical and radiological study with an interspinous distraction device. BMC Musculoskel Disord 17:90. https://doi.org/10.1186/ s12891-016-0945-7

6. Huang RC, Girardi FP, Cammisa FP et al (2005) Correlation between range of motion and outcome after lumbar total disc replacement: 8.6-year follow-up. Spine (Phila Pa 1976) 30:14071411. https://doi.org/10.1097/01.brs.0000166528.67425.0e

7. Leivseth G, Kolstad F, Nygaard OP et al (2006) Comparing precision of distortion-compensated and stereophotogrammetric Roentgen analysis when monitoring fusion in the cervical spine. Eur Spine J 15:774-779. https://doi.org/10.1007/s00586-005-0929-z

8. Halldin K, Zoëga B, Nyberg P et al (2005) The effect of standard lumbar discectomy on segmental motion: 5-Year follow-up using radiostereometry. Int Orthop 29:83-87. https://doi.org/10.1007/ s00264-005-0636-8

9. Nabhan A, Ahlhelm F, Pitzen T et al (2007) Disc replacement using Pro-Disc $\mathrm{C}$ versus fusion: a prospective randomised and controlled radiographic and clinical study. Eur Spine J 16:423-430. https://doi. org/10.1007/s00586-006-0226-5

10. Zoëga B, Kärrholm J, Lind B (1998) Plate fixation adds stability to two-level anterior fusion in the cervical spine: a randomized study using radiostereometry. Eur Spine J 7:302-307. https://doi. org/10.1007/s005860050079

11. Lind B, Zoëga B, Anderson PA (2007) A Radiostereometric Analysis of the Bryan ${ }^{\circledR}$ Cervical Disc Prosthesis. Spine (Phila Pa 1976) 32:885-890. https://doi.org/10.1097/01.brs.0000259925.11230.dd
12. Johnsson R, Strömqvist B, Aspenberg P (2003) Randomized radiostereometric study comparing osteogenic protein-1 (BMP7) and autograft bone in human noninstrumented posterolateral lumbar fusion. Spine (Phila Pa 1976) 27:2654-2661. https://doi. org/10.1097/00007632-200212010-00004

13. Bojan AJ, Bragdon C, Jönsson A et al (2015) Three-dimensional bone-implant movements in trochanteric hip fractures: precision and accuracy of radiostereometric analysis in a phantom model. J Orthop Res 33:705-711. https://doi.org/10.1002/jor.22822

14. Solomon LB, Stevenson AW, Callary SA (2010) The accuracy and precision of radiostereometric analysis in monitoring tibial plateau fractures. Acta Orthop 81(4):487-494. https://doi. org/10.3109/17453674.2010.487930

15. Ball J, Moore AD, Turner S (2008) Ball and Moore's Essential Physics for Radiographers, 4th edn. Blackwell Publishing, Richester

16. Laubenberger T, Laubenberger J (1999) Technik der medizinischen Radiologie. Diagnostik, Strahlentherapie, Strahlenschutz. Für Ärzte, Medizinstudenten und MTRA, 7. überarb. Deutscher Ärzte-Verlag, Köln

17. Scroll P, For D (2000) Accurate accuracy assessment: review of basic principles. Acta Orthop 71:106-108. https://doi.org/10.1080/00016 470052944017

18. McCalden RW (2005) Radiographic methods for the assessment of polyethylene wear after total hip arthroplasty. J Bone Jt Surg 87:2323. https://doi.org/10.2106/JBJS.E.00223

19. Humadi A, Dawood S, Halldin K, Freeman B (2017) RSA in spine: a review. Glob Spine J 7:811-820. https://doi.org/10.1177/21925 68217701722

20. Valstar ER, Gill R, Ryd L et al (2005) Guidelines for standardization of radiostereometry (RSA) of implants. Acta Orthop 76:563-572. https://doi.org/10.1080/17453670510041574

21. Köhnle H (1967) Röntgenstereoverfahren. In: Bergerhoff W et al (eds) Handbuch der medizinischen Radiologie Encyclopedia of Medical Radiology. Springer, Berlin

22. Loewenhardt B (2006) Bildgebende diagnostik technik anatomie pathologie, 3rd edn. Wissenschaftlicher Selbstverlag, Fulda

23. Park S-A, Fayyazi AH, Ordway NR et al (2009) Correlation of radiostereometric measured cervical range of motion with clinical radiographic findings after anterior cervical discectomy and fusion. Spine (Phila Pa 1976) 34:680-686. https://doi.org/10.1097/BRS.0b013 e31819819a0

24. Seehaus F, Emmerich J, Kaptein BL et al (2009) Experimental analysis of model-based roentgen stereophotogrammetric analysis (MBRSA) on four typical prosthesis components. J Biomech Eng 131:041004. https://doi.org/10.1115/1.3072892

25. Gilad I, Nissan M (1986) A study of vertebra and disc geometric relations of the human cervical and lumbar spine. Spine 11:154-157. https://doi.org/10.1097/00007632-198603000-00010

26. Xia Q, Wang S, Kozanek M et al (2010) In-vivo motion characteristics of lumbar vertebrae in sagittal and transverse planes. J Biomech 43:1905-1909. https://doi.org/10.1016/j.jbiomech.2010.03.023

27. Mann KS, Kurudirek M, Sidhu GS (2012) Verification of dosimetric materials to be used as tissue-substitutes in radiological diagnosis. Appl Radiat Isot 70:681-691. https://doi.org/10.1016/j.aprad iso.2011.12.008

28. Medis specials B (2010) Model-based RSA Software 3.3, supplied by Medis specials, Leiden, The Netherlands

29. Martin Bland J, Altman DG (1986) Statistical methods for assessing agreement between two methods of clinical measurement. Lancet 327:307-310

30. Bragdon CR, Malchau H, Yuan X et al (2002) Experimental assessment of precision and accuracy of radiostereometric analysis for the determination of polyethylene wear in a total hip replacement model. J Orthop Res 20:688-695. https://doi.org/10.1016/S0736 -0266(01)00171-1 
31. Sköldenberg O, Ödquist M (2011) Measurement of migration of a humeral head resurfacing prosthesis using radiostereometry without implant marking: an experimental study. Acta Orthop 82:193-197. https://doi.org/10.3109/17453674.2011.566133

32. Soderkvist I, Wedin PA (1993) Determining the movements of the skeleton using well-configured markers. J Biomech 26:1473-1477

33. Lee S, Harris KG, Nassif J et al (1993) In Vivo Kinematics of the Cervical Spine. Part I J Spinal Disord 6:522-534. https://doi. org/10.1097/00002517-199306060-00008

34. Yuan X, Ryd L (2000) Accuracy analysis for RSA: A computer simulation study on 3D marker reconstruction. J Biomech 33:493-498. https://doi.org/10.1016/S0021-9290(99)00182-7

35. Söderkvist I, Wedin P- $\AA$ (1994) On condition numbers and algorithms for determining a rigid body movement. BIT 34:424-436. https://doi.org/10.1007/BF01935651
36. Kibsgård TJ, Røise O, Stuge B, Röhrl SM (2012) Precision and accuracy measurement of radiostereometric analysis applied to movement of the sacroiliac joint. Clin Orthop Relat Res 470:31873194. https://doi.org/10.1007/s11999-012-2413-5

Publisher's Note Springer Nature remains neutral with regard to jurisdictional claims in published maps and institutional affiliations. 